\title{
Article \\ Self-Powered Flexible Sour Sensor for Detecting Ascorbic Acid Concentration Based on Triboelectrification/Enzymatic-Reaction Coupling Effect
}

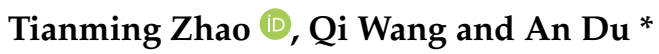 \\ College of Sciences, Northeastern University, Shenyang 110819, China; zhaotm@stumail.neu.edu.cn (T.Z.); \\ wangqi@mail.neu.edu.cn (Q.W.) \\ * Correspondence: du_an_neu@126.com
}

check for updates

Citation: Zhao, T.; Wang, Q.; Du, A. Self-Powered Flexible Sour Sensor for

Detecting Ascorbic Acid

Concentration Based on

Triboelectrification/EnzymaticReaction Coupling Effect. Sensors 2021, 21, 373. https://doi.org/ $10.3390 / \mathrm{s} 21020373$

Academic Editor: Fabio Zaza Received: 28 November 2020 Accepted: 3 January 2021 Published: 7 January 2021

Publisher's Note: MDPI stays neutral with regard to jurisdictional clai$\mathrm{ms}$ in published maps and institutional affiliations.

Copyright: (C) 2021 by the authors. Licensee MDPI, Basel, Switzerland. This article is an open access article distributed under the terms and conditions of the Creative Commons Attribution (CC BY) license (https:// creativecommons.org/licenses/by/ $4.0 /)$.

\begin{abstract}
Artificial sensory substitution systems can mimic human sensory organs through replacing the sensing process of a defective sensory receptor and transmitting the sensing signal into the nervous system. Here, we report a self-powered flexible gustation sour sensor for detecting ascorbic acid concentration. The material system comprises of $\mathrm{Na}_{2} \mathrm{C}_{2} \mathrm{O}_{4}$-Ppy with AAO modification, PDMS and $\mathrm{Cu}$ wire mesh. The working mechanism is contributed to the triboelectrification/enzymatic-reaction coupling effect, and the device can collect weak energy from body movements and directly output triboelectric current without any external power-units. The triboelectric output is affected by AA concentration, and the response is up to $34.82 \%$ against $15.625 \mathrm{mM} / \mathrm{L}$ of AA solution. Furthermore, a practical application in detecting ascorbic acid concentration of different drinks has been demonstrated. This work can encourage the development of wearable flexible electronics and this self-powered sour sensor has the potential that can be acted as a kind of gustatory receptors to build electronic tongues.
\end{abstract}

Keywords: ascorbic acid detection; self-powered; sour sensor; triboelectrification/enzymatic-reaction coupling effect

\section{Introduction}

The internet of things (IoT) is a huge network integrated with sensors in order to interface with our daily lives through data exchanging [1-5]. Furthermore, in recent years, the establishment of body-electric interfaces has attracted notable attention via multifarious electronic skins for capturing indexed in big data analytics [6-10]. Some devices can detect toxic agents in the environment and define the quality of the food, and some devices can reflect the human body movement state and physiological information [11-26]. For example, sensors for gustation recognition are immersed in the measured solution, and the changes of the electrical signal can recognize the flavor [27-31]. These traditional sensors are usually based on potentiometer, voltammetry and impedimetric titration, which have a wide range of detections [32-37]. However, the power-supply units integrated with the sensing systems limit the development of innovative portable gustation devices. The bulky volume of the sensing systems reduces the comfort level and low capacity and frequent charge/discharge process of the power-supply units increase the risk for safe problems, which are still bottlenecks to be overcome [38,39]. Thus, a new kind of gustation electronic tongue is given an opportunity to build self-powered system in day-today application.

Recently, the wearable piezoelectric/triboelectric nanogenerators as a self-powered system can actively output electrical signal though harvesting tiny mechanical energy from the human body and the electrical signal can reflect the human body movement state or physiological information at the same time [40-43]. Furthermore, through modifying enzymes, the piezoelectric/triboelectric process can be affected by enzymatic reactions. In our 
previous work, self-powered electronic skins by modifying glucose oxidase for sensing glucose in sweat has been obtained [44-46]. Basing on triboelectrification/enzymatic-reaction coupling effect, the triboelectric outputting current signal can act as not only electric energy but also biosignal which is depended on the glucose concentration. Thus, by redesigning the structure of the device and material system, a new self-powered gustation electronic tongue for sensing sour taste can be achieved.

In this paper, a self-powered flexible sour sensor for mimicking taste buds has been put forward through a simple way. This self-powered sour sensor is fabricated from $\mathrm{Na}_{2} \mathrm{C}_{2} \mathrm{O}_{4}$ doped polypyrrole/polydimethylsiloxane $\left(\mathrm{Na}_{2} \mathrm{C}_{2} \mathrm{O}_{4}-\mathrm{Ppy} / \mathrm{PDMS}\right)$ nanostructures. PDMS and $\mathrm{Na}_{2} \mathrm{C}_{2} \mathrm{O}_{4}$-Ppy have reported that both materials have excellent biocompatibility. In addition, $\mathrm{Na}_{2} \mathrm{C}_{2} \mathrm{O}_{4}$-Ppy are synthesized through electrochemical polymerization process. Ascorbate acid oxidase (AAO) is modified on the surface of Ppy layer. Basing on triboelectrification/enzymatic-reaction coupling effect, this sour sensor can convert weak energy into the current signal and this signal is markedly dependent on the concentration of ascorbic acid. Furthermore, the whole process does not involve any extra power source. At last, a practical application for sensing ascorbic acid concentration five samples has been demonstrated. Our work can encourage the development of wearable flexible electronics and develop a new direction for building electronic tongues.

\section{Materials and Methods}

\subsection{Materials}

Polydimethylsiloxane (PDMS) and copper wire mesh were purchased from Taobao. Pyrrole was bought from Sinopharm Chemical Reagent Co., Ltd. (Beijing, China). Sodium oxalate $\left(\mathrm{Na}_{2} \mathrm{C}_{2} \mathrm{O}_{4}\right)$, sodium persulfate, phosphate buffer saline (PBS), glucose, uric acid (UA), urea and ascorbic acid (AA) were purchased from Shanghai Aladdin Biochemical Technology Co. Ltd. (Shanghai, China). Ascorbate acid oxidase (AAO) was provided by Shanghai Lanji Technology Development Co., Ltd. (Shanghai, China).

\subsection{Device Fabrications}

Copper wire mesh was washed by deionized water and alcohol several times to remove the impurities and dried in $\mathrm{N}_{2}$ flow at $60^{\circ} \mathrm{C}$. PDMS was mixed with a mass ratio of 10:1 by elastomer and cross-linker under ultrasonic bath $(40 \mathrm{kHz}, 80 \mathrm{~W})$ for $30 \mathrm{~min}$ at room temperature $\left(\sim 20^{\circ} \mathrm{C}\right)$. Then the mixture was placed in a vacuum oven to obtain the air-free PDMS. The air-free PDMS colloid was poured into a box and put in a vacuum oven at $90^{\circ} \mathrm{C}$ for $8 \mathrm{~min}$. Next, the precleaned copper wire mesh was cut into pieces $(2 \mathrm{~cm} \times 5 \mathrm{~cm})$ and put on the PDMS before being completely solidified. Finally, the copper-wire-mesh/PDMS film was solidified in a vacuum oven at $90^{\circ} \mathrm{C}$ for $2 \mathrm{~h}$. It was worth highlighting that the firstcuring-process must be conducted and in this case, the copper wire could be immobilized on the surface of the PDMS rather than embedding in the PDMS layer. After solidification process, the film was immersed into the sodium persulfate aqueous solution $(0.1 \mathrm{~m} / \mathrm{L})$ for $30 \mathrm{~s}$ (wet-etching process). The transient wet-etching process would remove less $\mathrm{Cu}$ and $\mathrm{Cu}$ mesh that was still on the surface of PDMS. Furthermore, this process aimed to form growth space for electrochemical polymerization of $\mathrm{Na}_{2} \mathrm{C}_{2} \mathrm{O}_{4}$ doped polypyrrole $\left(\mathrm{Na}_{2} \mathrm{C}_{2} \mathrm{O}_{4}\right.$-Ppy). The $\mathrm{Na}_{2} \mathrm{C}_{2} \mathrm{O}_{4}$-Ppy on the surface of copper wire mesh was synthesized via electrochemical polymerization. $\mathrm{Cu}$ mesh of the device was used as working electrode to deposit $\mathrm{Na}_{2} \mathrm{C}_{2} \mathrm{O}_{4}-\mathrm{Ppy}, \mathrm{Ag} / \mathrm{AgCl}$ was used as the reference electrode and $\mathrm{Pt}$ wire was used as the counter electrode, respectively. Cyclic voltammetry mode was conducted from $1.2 \mathrm{~V}$ to $-1.2 \mathrm{~V}$ for $400 \mathrm{~s}$ and the polymerization solution contained $0.1 \mathrm{M} / \mathrm{L}$ pyrrole monomer and $0.2 \mathrm{M} / \mathrm{L} \mathrm{Na}_{2} \mathrm{C}_{2} \mathrm{O}_{4}$. Then, the $\mathrm{Cu}$ film $(\sim 200 \mathrm{~nm})$ was deposited by electron beam evaporation equipment. Finally, the surface was washed by deionized water for several times and dried overnight.

Ten milligrams AAO was dissolved in $10 \mathrm{~mL}$ PBS. Then $0.5 \mathrm{~mL}$ AAO solution was dropped on the device for four times and an incubation procedure was conducted in a fume hood for $8 \mathrm{~h}$. The prepared devices were stored at $4{ }^{\circ} \mathrm{C}$. 


\subsection{Characterization and Measurement}

The microstructure of the device was examined by Scanning electron microscopy (SEM, Hitachi S4800). The electron beam evaporation equipment (DZS500, Pengcheng Vacuum Technique, Inc., Xuzhou, China) was used to deposit $\mathrm{Cu}$ back electrode. The electrochemical workstation (CHI627D, CH Instruments, Inc., Austin, TX, USA) was used to synthesize the $\mathrm{Na}_{2} \mathrm{C}_{2} \mathrm{O}_{4}$-Ppy. The measurement system contained a controller and an actuator, which can set driving force, moving speed, moving distance and cycling time. Figure S1 showed the photograph of the measurement system. The data was collected by Stanford SR 560 (a low-noise preamplifier). The temperature was conducted at $\sim 20^{\circ} \mathrm{C}$ and the relative humidity was kept at $40 \%$. Each kind of measurement was replicated 10 times.

\section{Results}

\subsection{Experimental Design}

As shown in Figure 1a, approximately 10,000 taste receptors named as taste buds grow on the surface of the tongue. These taste buds can be stimulated during chewing course and transport bioelectric signal to the specific encephalic region through afferent fibers, telling what the flavors are (Figure $1 b$ ). The design of self-powered flexible sour sensor can collect weak energy from body movements and actively output current signal. By modifying AAO, the enzymatic reaction can control the triboelectrification process and the output triboelectric current is depended on AA concentration. The friction materials are PDMS and Ppy. PDMS and Ppy are reported by their excellent biocompatible and considerable gap of electronegativity. PDMS can easily capture electrons from Ppy and leave the equal numbers charges on the surface of Ppy layer [47-49]. Thus, this self-powered flexible sour sensor overcomes the bottleneck of the power source. Furthermore, the fabrication of the device is shown in Figure 1c. The process of fabrication contains solidification, wet-etching, electrochemical polymerization, depositing electrodes and modifying enzyme. More details can be seen in Section 2. It is worth mentioning that the solidification time must be strictly obeyed. $\mathrm{Na}_{2} \mathrm{C}_{2} \mathrm{O}_{4}-\mathrm{Ppy}$ can be only deposited on half-submerged copper wire mesh. A large area device can be obtained in this simple way, and the large area device can be cut into suitable pieces for measurement. Figure $1 \mathrm{~d}$ shows the measurement system, containing a controller and an actuator, which can set driving force, moving speed, moving distance and cycling time. The device is nailed to the actuator. When the actuator is forward (Figure 1di), the device will be deformed and when the actuator is backward, the device will be restored to the original state (Figure 1dii). The triboelectric current output when the device is under deformation and the data can be collected by SR 560. The different concentration of AA, uric acid (UA), glucose and urea solutions are dropped on the surface of the devices for the measurements. Figure S1a shows the photograph of the measurement system and Figure S1b shows the details of the device. The working frequencies and angles can be calculated according to the driving force, moving speed, moving distance and cycling time. 
(a)

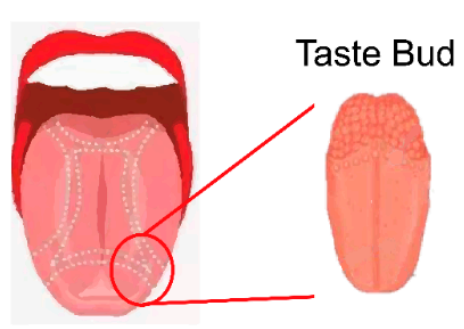

(b)

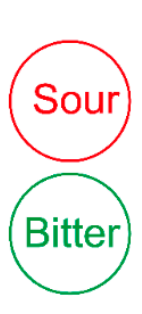

Taste Bud

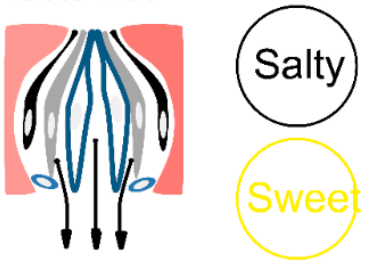

Afferent Fibers

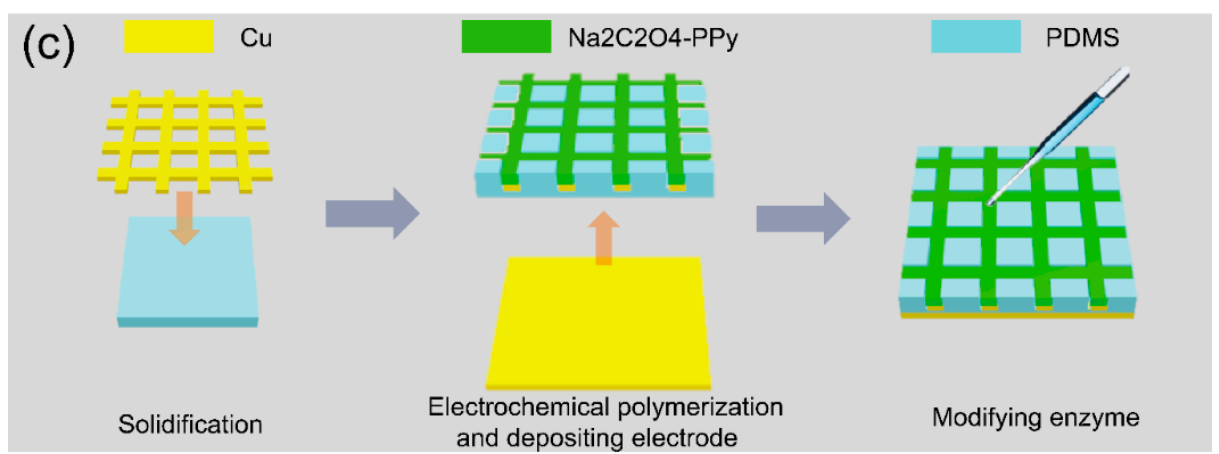

(d) and depositing electrode

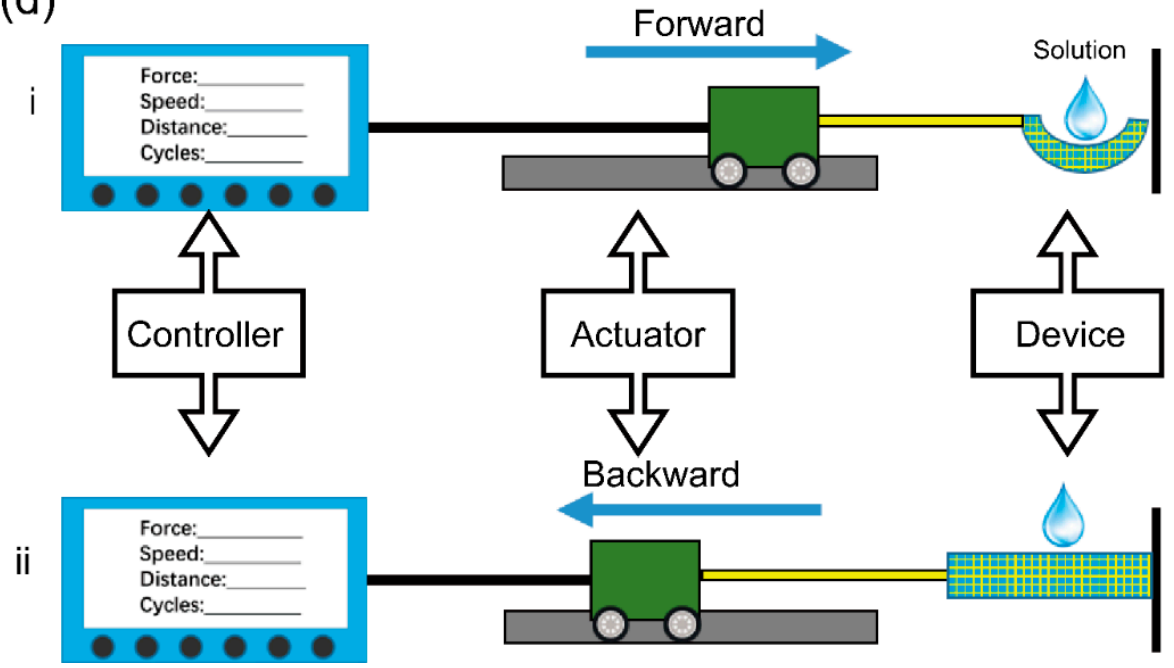

Figure 1. (a) Taste receptor: taste bud. (b) Gustation recognition. (c) The fabrication of the device. (d) The measurement system.

\subsection{Characterization of the Self-Powered Sour Sensor}

Figure 2 demonstrates the images of self-powered sour sensor. Figure 2a shows the SEM image of copper-wire-mesh/PDMS film. It can be manifestly seen the copper wire mesh is half immersed in the PDMS layer, which should be firmly fixed in PDMS. Figure $2 \mathrm{~b}$ shows the SEM image of copper-wire-mesh/PDMS film after wet-etching. After the wet-etching process, there is a gap between PDMS and copper wire mesh, providing growth space of the $\mathrm{Na}_{2} \mathrm{C}_{2} \mathrm{O}_{4}$-Ppy. Furthermore, this gap provides sufficient interval between the $\mathrm{Na}_{2} \mathrm{C}_{2} \mathrm{O}_{4}$-Ppy and PDMS for friction. Figure $2 \mathrm{c}$ shows the SEM image rub with of the device after electrochemical deposition. A rough surface of the Ppy film can effectively PDMS layer, increasing the triboelectrification process. Figure $2 \mathrm{~d}$ shows an optical image of the device. The device is so adaptable to fit human skin. 

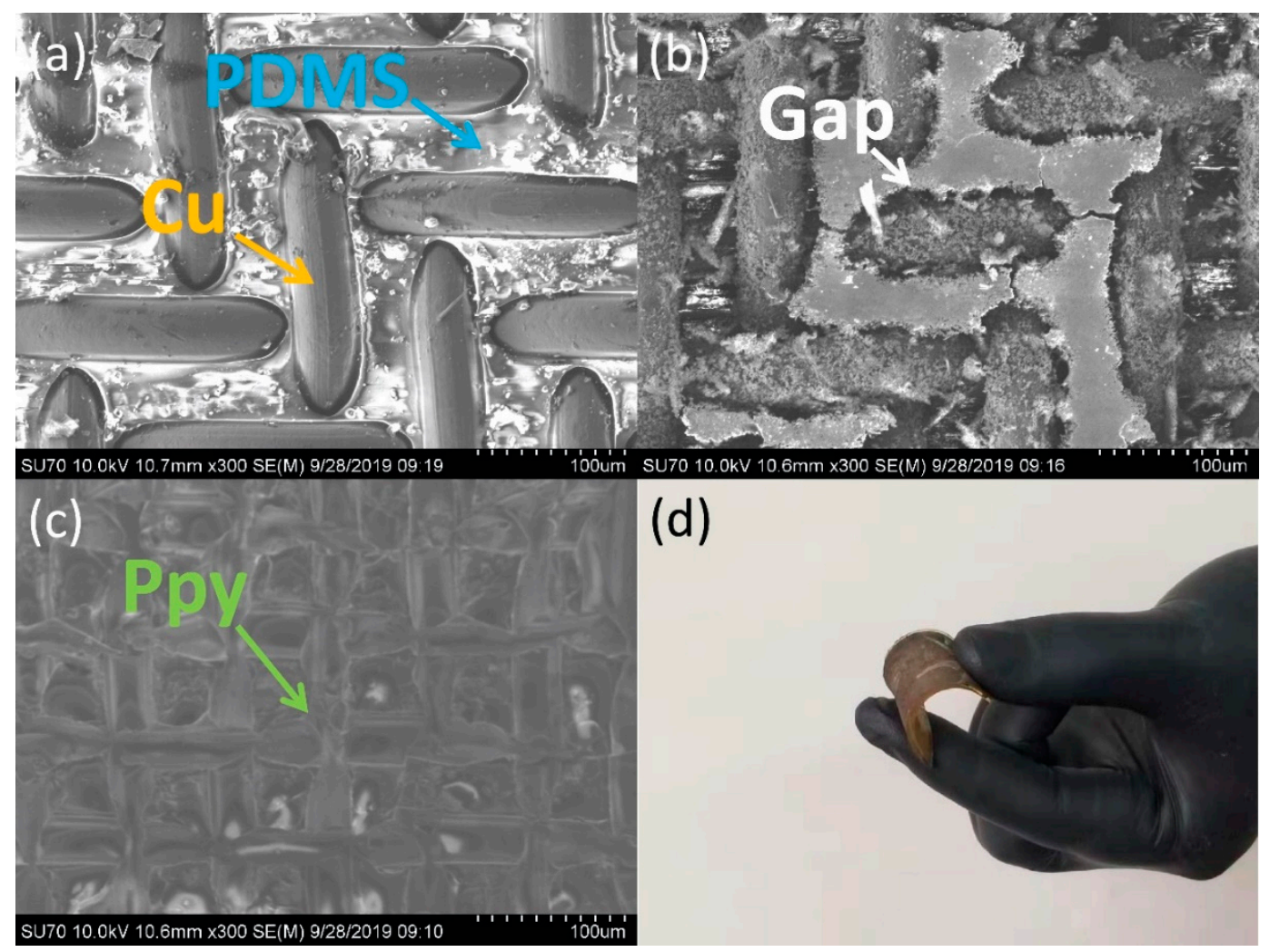

Figure 2. The characterization of self-powered sour sensor. (a) SEM image of copper-wire-mesh/PDMS film. (b) SEM image of copper-wire-mesh/PDMS film after wet-etching. (c) SEM image of the device after electrochemical deposition. (d) The optical image of the self-powered sour sensor.

\section{Discussion}

\subsection{Sour Sensing Performances}

Self-powered flexible sour sensor for AA detection can actively output triboelectric current signal which is dependent on AA concentration and the AA biosensing performance has been presented in Figure 3. The self-powered sour sensor is connected to the external circuit for testing the AA biosensing performance against the AA concentration from 0.005 to $15.625 \mathrm{mM} / \mathrm{L}$. All the experimental measurements are carried out at room temperature. The deformation on the device is conducted by a stepping motor, of which the movement can be monitored by programming. The bending angles and frequencies are programmed to $15^{\circ}$ and $1 \mathrm{~Hz}$, respectively. As shown in Figure 3a, the output triboelectric current is markedly dependent on the AA concentration, and the triboelectric current signal decreases with the increasing AA concentration. As the concentration of AA is 0.005, $0.025,0.125,0.625,3.23$ and $15.625 \mathrm{mM} / \mathrm{L}$, the output triboelectric current is $6.67 \pm 0.20$, $5.56 \pm 0.14,5.13 \pm 0.08,4.85 \pm 0.16,4.62 \pm 0.08$ and $4.35 \pm 0.10 \mathrm{nA}$, respectively. Figure $3 \mathrm{~b}$ shows enlarged views of output triboelectric current at the AA concentration of 0.0025 and $3.125 \mathrm{mM} / \mathrm{L}$, respectively. It can be seen from the stability of the output triboelectric current at different AA concentration. A control experiment is designed to verify the triboelectrification/enzymatic-reaction coupling effect of the device, as shown in Figure 3c,d. Figure 3c shows the relationship between AA concentration and output triboelectric current of the device with AAO modification, and the red line (from 0.025 to $15.625 \mathrm{mM} / \mathrm{L}$ ) is a linear fit. The linear fitting of Equation is as follows:

$$
\mathrm{y}=4.81-0.40 \times \lg (\mathrm{x}),
$$


where $y$ represents the triboelectric current $(\mathrm{nA})$ and $\mathrm{x}$ represents the AA concentration $(\mathrm{mM} / \mathrm{L})$. Furthermore, the linearity is up to 0.985 . The upper limit of detection is $15.625 \mathrm{mM} / \mathrm{L}$ and the lower limit of detection is $0.0025 \mathrm{mM} / \mathrm{L}$. Figure $3 \mathrm{~d}$ shows the relationship between AA concentration and output triboelectric current of the device without modifying AAO. It can be manifestly observed that the device without AAO modification does not have the AA sensing performance. The totally distinct behaviors of the two devices indicate that enzymatic reaction can control the triboelectrification process. The output triboelectric current can be regarded as a function of AA concentration, as shown in Figure 3e. The response of the device can be calculated from the following equation:

$$
R \%=\frac{\left|I_{0}-I_{t}\right|}{I_{0}} \times 100 \%,
$$

where $I_{0}$ and $I_{t}$ represent the output triboelectric current in $0.005 \mathrm{mM} / \mathrm{L}$ and others AA concentration solution, respectively. For the device with AAO modification (Group 1), as the concentration of AA is $0.005,0.025,0.125,0.625,3.125$ and $15.625 \mathrm{mM} / \mathrm{L}$, the corresponding response is $16.74 \%, 23.21 \%, 27.31 \%, 30.71 \%$ and $34.82 \%$, respectively. Furthermore, for the device without AAO modification (Group 2), as the concentration of AA is $0.005,0.025$, $0.125,0.625,3.23$ and $15.625 \mathrm{mM} / \mathrm{L}$, the corresponding response is $3.02 \%, 4.80 \%, 4.30 \%$, $0.04 \%$ and $1.19 \%$, respectively. As shown in Figure 3f, only adding water on the surface of the device with AAO modification, the triboelectric is almost a constant. In addition, the response is $0,2.03 \%, 0.03 \%, 0.3 \%, 0.03 \%$ and $0.8 \%$, respectively. Figure $3 g$ shows the response of the device with AAO modification during 8 days against AA solutions $(15.625 \mathrm{mM} / \mathrm{L})$. The response is $34.82 \%, 35.42 \%, 30.41 \%, 22.14 \%$ and $10.98 \%$ in five days and after replenishing AAO, the response restore to $36.41 \%, 34.14 \%$ and $32.64 \%$. The device is effective for 3-5 days due to the activity of AAO. However, this problem can be solved by replenishing AAO regularly.

Figure 4 shows the influence of the bending angles on the AA biosensing performance of the self-powered flexible sour sensor. The concentration of AA is conducted in 0.005 and $3.125 \mathrm{mM} / \mathrm{L}$, respectively. Figure 4a shows the output triboelectric current of self-powered flexible gustation sour sensor under different bending angles. As the bending angles are $15^{\circ}, 30^{\circ}, 45^{\circ}$ and $60^{\circ}$, the output triboelectric current against $0.005 \mathrm{mM} / \mathrm{L}$ of AA solution $\left(I_{0}\right)$ is $6.96 \pm 0.47,5.34 \pm 0.28,4.33 \pm 0.17$ and $3.48 \pm 0.16 \mathrm{nA}$, and the output triboelectric current against $3.125 \mathrm{mM} / \mathrm{L}$ of AA solution $\left(I_{t}\right)$ is $5.83 \pm 0.32,4.18 \pm 0.45,3.70 \pm 0.28$ and $2.50 \pm 0.28 \mathrm{nA}$, respectively (Figure $4 \mathrm{~b}$ ). The relationship between response and angle can be seen in Figure $4 \mathrm{~b}$. As the bending angles are $15^{\circ}, 30^{\circ}, 45^{\circ}$ and $60^{\circ}$, the response of the device against $3.125 \mathrm{mM} / \mathrm{L}$ of AA solution is $16.27 \%, 27.74 \%, 14.5 \%$ and $28.15 \%$, respectively. Though the output triboelectric current decreases with the increasing bending angles, the response is almost the same. These results show that self-powered flexible sour sensor have excellent flexibility and stability for its practical applications. 
(a)
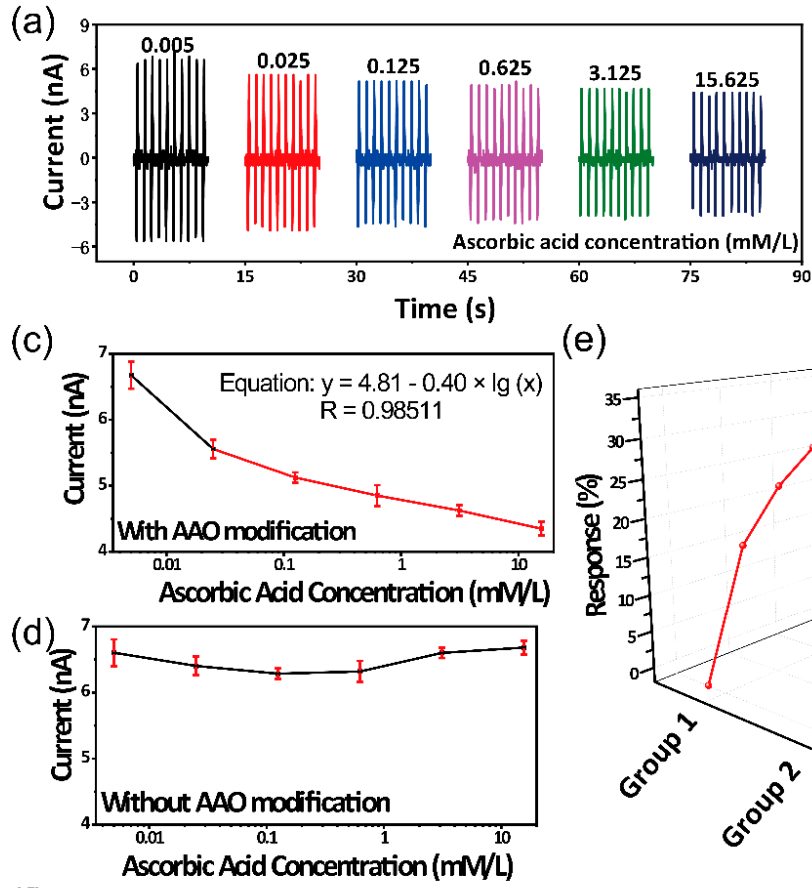

(e)
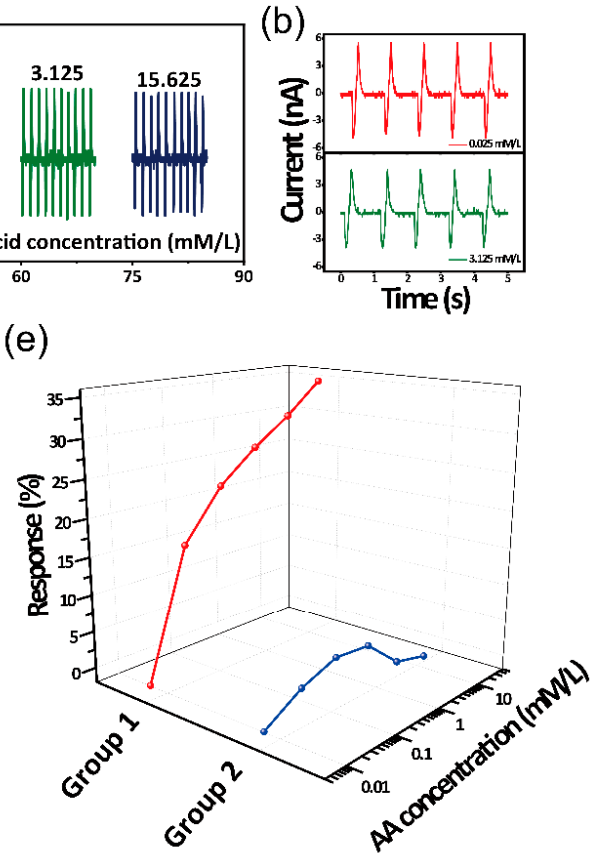

(f)
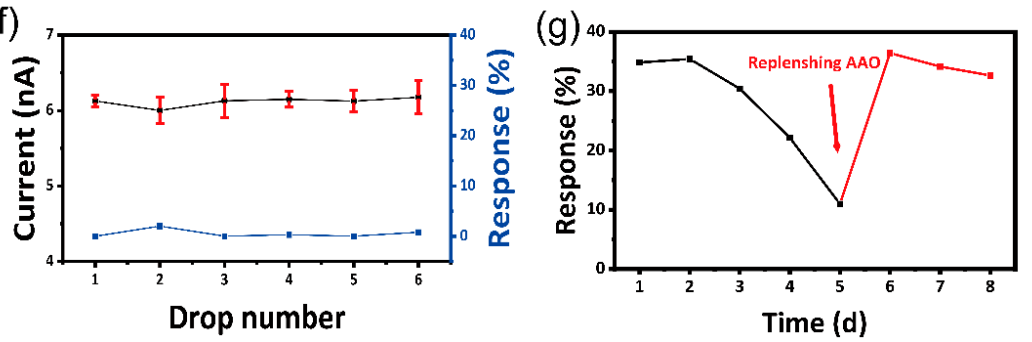

Figure 3. The AA biosensing performance of the self-powered sour sensor. (a) The output triboelectric current of the device against AA with the concentration from 0.005 to $15.625 \mathrm{mM} / \mathrm{L}$. (b) The enlarged views of output triboelectric current at the AA concentration of 0.0025 and $3.125 \mathrm{mM} / \mathrm{L}$, respectively. (c) The output triboelectric current of the device with AAO modification against AA with the concentration from 0.005 to $15.625 \mathrm{mM} / \mathrm{L}$, respectively. Red line is the limit of detection. (d) The output triboelectric current of the device without AAO modification against AA with the concentration from 0.005 to $15.625 \mathrm{mM} / \mathrm{L}$, respectively. (e) Response of two control experiments. (f) The triboelectric current and response of the sour sensor by adding deionized water. (g) The response of the sour sensor during 8 days.

(a)

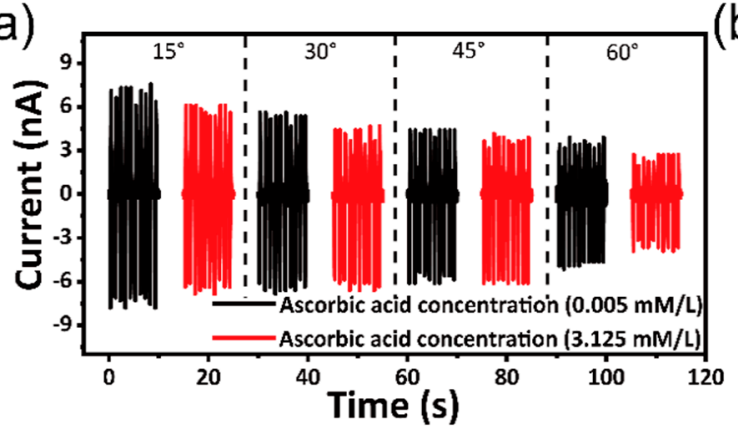

(b)

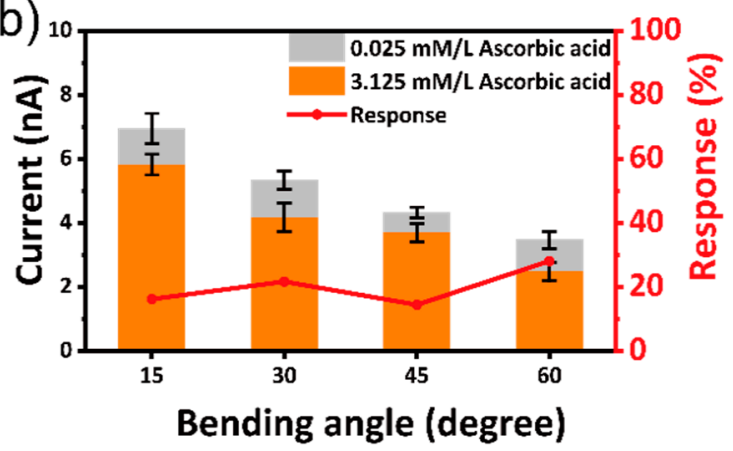

Figure 4. (a) Output triboelectric current of self-powered flexible sour sensor under different bending angles. (b) The relationship between bending angles and response. 


\subsection{Sensing Mechanism}

To further confirm the sensing mechanism for AA, some common compounds in body have been tested. As shown in Figure 5a, increasing the concentration of the uric acid solution cannot lower the output triboelectric current. Furthermore, the similar results can be observed in Figure 5b,c. The device modified with AAO cannot detect urea and glucose. These results imply that the lowered output triboelectric current of the devices is due to the AA concentration. Only increasing the concentration of the AA solution can decrease the output triboelectric current. Furthermore, the increasing concentration of uric acid, glucose and urea cannot influence the output triboelectric current of the self-powered flexible sour sensor.

(a)

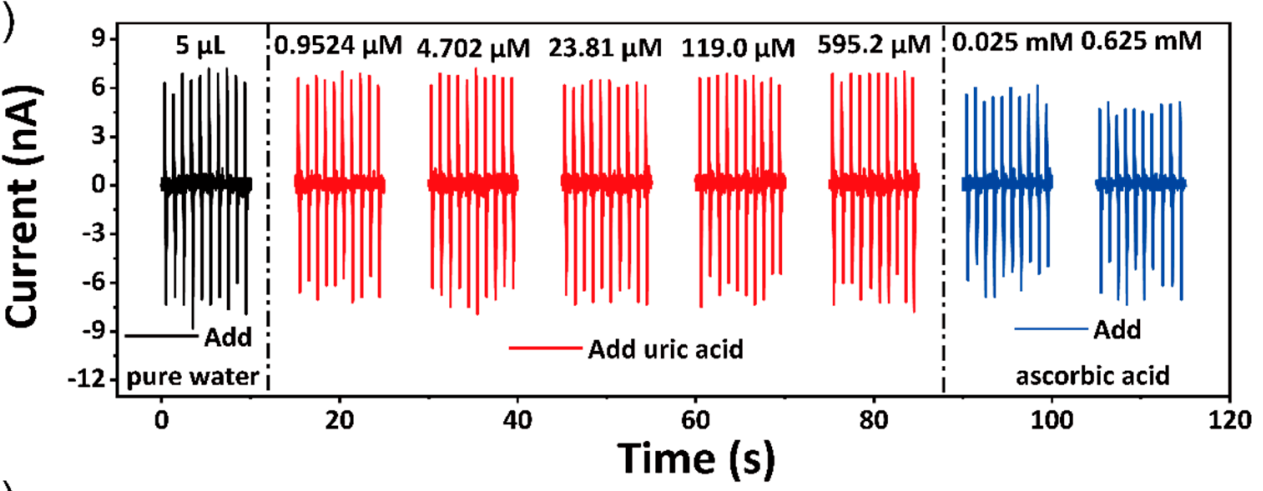

(b)
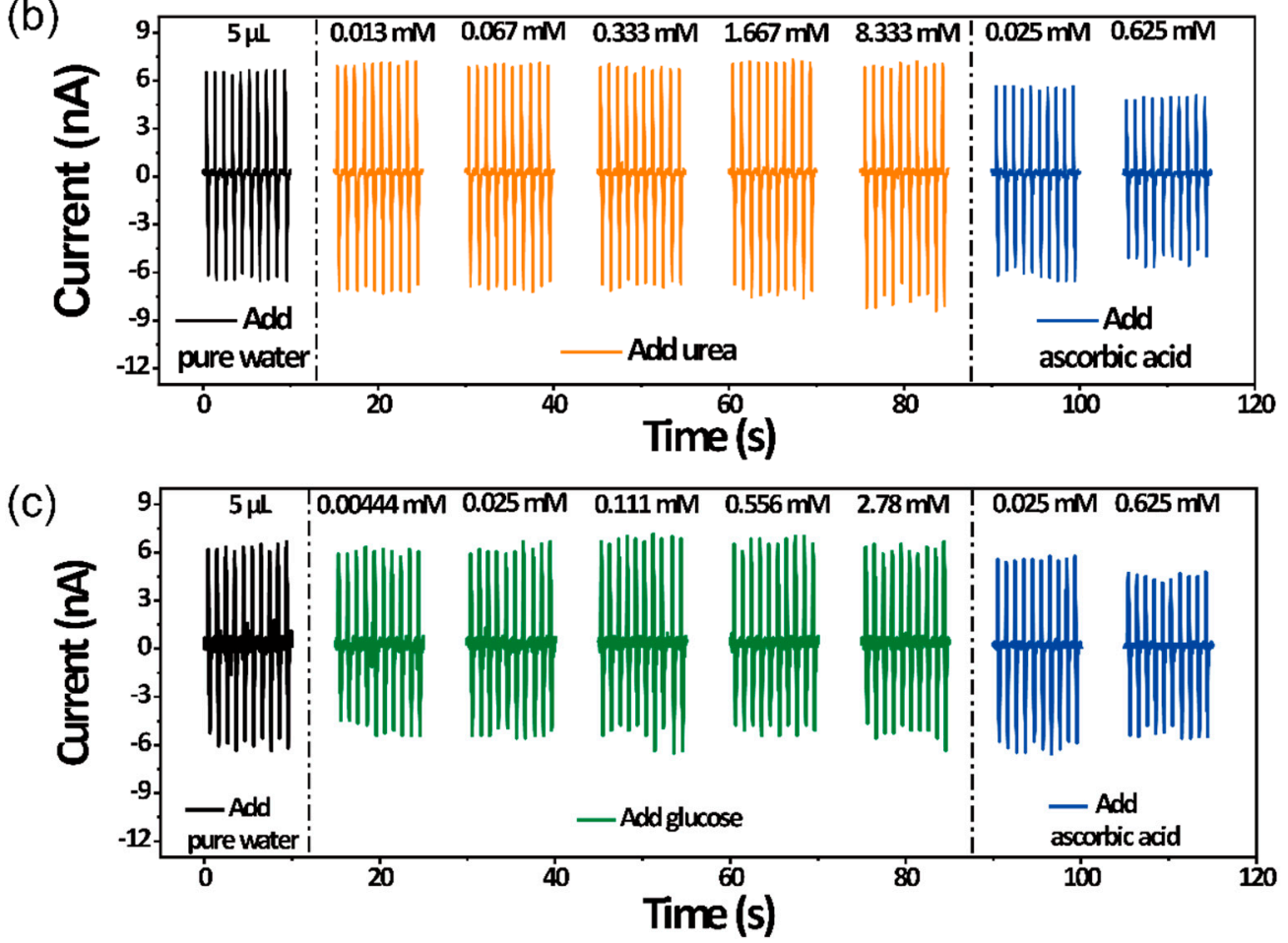

Figure 5. Control experiments. (a) Influence of different uric acid concentrations. (b) Influence of different glucose concentrations. (c) Influence of different urea concentrations.

The working mechanism of self-powered flexible sour sensor is shown in Figure 6. Figure $6 \mathrm{a}, \mathrm{b}$ show self-powered flexible sour sensor and one sensing unit of the device. Blue part, green part and yellow part represent PDMS, Ppy and $\mathrm{Cu}$, respectively. Furthermore, the red torus knot represents AAO. After incubation procedure, AAO is immobilized onto the surface of Ppy. The triboelectrification process between PDMS and Ppy is shown in Figure 6c [36,50]. In the initial state, the PDMS layer and Ppy layer start to rub. Due to 
the triboelectric effect, the charges accumulate on the contact area. Because PDMS is more electronegative than Ppy, negative charges accumulate on the PDMS layer and the positive charges accumulate on the Ppy layer. Then, the PDMS and Ppy are separated from each other due to the deformation, and the charges are contained in PDMS layer and Ppy layer, respectively. With the increasing separated distance, the positive charges migrate from the Ppy layer to the $\mathrm{Cu}$ back electrode via the external circuit under the electrostatic field. Furthermore, when the separated distance increase to the max, the charges stop migrating from Ppy layer to the $\mathrm{Cu}$ back electrode. When the PDMS layer and Ppy layer come into contact due to the deformation, the charges move in reverse (from $\mathrm{Cu}$ back electrode to Ppy layer). During the electricity generation process, the output can be detected by Stanford SR 560 via the external circuit. The theoretical real-time electricity generation of the triboelectrification effect can be described by the equations as follows [51-53]:

$$
Q_{S C}=\frac{\sigma_{i} S g(t)}{d+x},
$$

where $Q_{S C}$ represents the triboelectric charge; $\sigma_{i}$ represents the triboelectric charge density of Ppy; $S$ represents the contact area; $d$ represents the separation distance; $g(t)$ represents the separation distance between the copper wire mesh and Ppy (a function of time); $x$ represents the maximum of the separation distance; and $I_{S C}$ represents the theoretical outputting current.

(a)

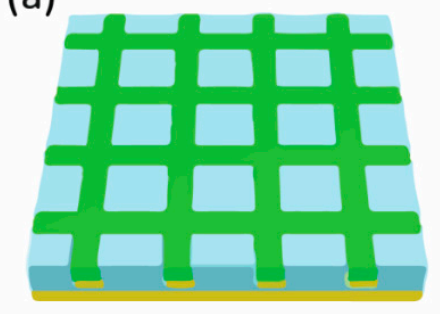

(b)

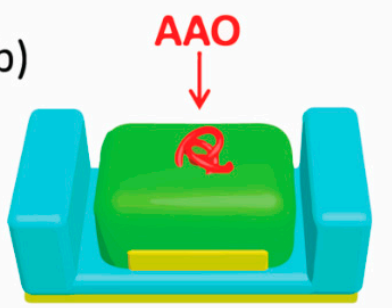

Sensing unit (c)
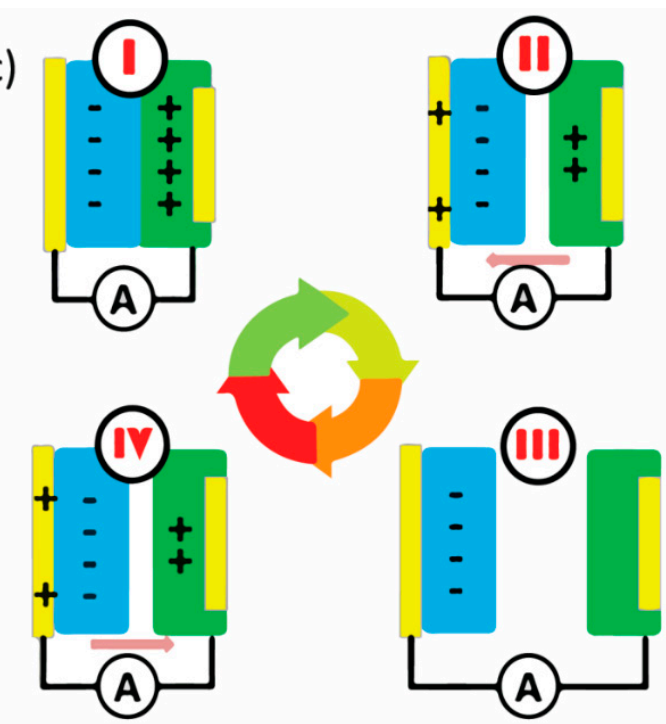

(d)

\section{$\mathrm{AA}+\mathrm{AAO}_{\mathrm{ox}} \longrightarrow \mathrm{DHA}+\mathrm{AAO}_{\mathrm{red}}+2 \mathrm{H}^{+}$}

Figure 6. The working mechanism of the self-powered flexible sour sensor. (a) The self-powered flexible sour sensor. (b) One sensing unit. (c) The electricity generation process. (d) The enzymatic reaction: $\mathrm{AA}$ and $\mathrm{AAO}$.

The enzymatic reaction can control the triboelectrification process and Figure $6 \mathrm{~d}$ shows the production of the enzymatic reaction of AA and AAO [54]. When the enzymatic reaction is carried out, Ppy is exposed to $\mathrm{H}^{+}$ions. Due to the deprotonation behavior of Ppy, the surface chemical state transforms into Ppyox. During the triboelectrification process, the gap of electronegative between PDMS and Ppy reduces and fewer charges can be driven through the external circuit, which reduces the output triboelectric current. Furthermore, with the AA concentration increasing, the more $\mathrm{H}^{+}$ions release from the enzymatic reaction, resulting in the lower output triboelectric current. Thus, the output 
triboelectric current can be regarded as both power and biosensing signal and the device does not need any external power source.

\subsection{Applications}

Figure 7 shows a practical application of this self-powered flexible sour sensor for detecting ascorbic acid against mineral water (Figure 7a), apple juice (Figure 7b), compound juice (Figure 7c), orange juice (Figure 7d) and vitamin drink (Figure 7e), respectively. These drinks can be bought from shops and the concentration of ascorbic acid can be found in Nutrition Facts. Furthermore, the AA concentrations of these drinks have been shown in Figure S2. The AA concentration of apple juice is $0.426 \mathrm{mM} / \mathrm{L}$ (Figure S2a), the AA concentration of compound juice is $1.275 \mathrm{mM} / \mathrm{L}$ (Figure S2b), the AA concentration of apple juice is $0.426 \mathrm{mM} / \mathrm{L}$ (Figure S2c) and the AA concentration of vitamin drink is $1.136 \mathrm{mM} / \mathrm{L}$ (Figure S2d), respectively. The solutions are dropped on the surface of the self-powered sour sensor, and the triboelectric actively output under the deformation. Figure 7a-e shows the triboelectric current against mineral water (Figure 7a), apple juice (Figure 7a), compound juice (Figure 7c), orange juice (Figure $7 \mathrm{~d}$ ) and vitamin drink (Figure 7e), respectively. The triboelectric current is $4.98 \pm 0.22,4.71 \pm 0.48,4.94 \pm 0.26$ and $4.79 \pm 0.12 \mathrm{nA}$ against mineral water, apple juice, compound juice, orange juice and vitamin drink, respectively. As shown in Figure $7 \mathrm{f}$, the concentrations of these drinks are measured and the red line is actual value and green line is experimental value. The concentrations of these drinks are calculated using Equation (1). The experimental concentrations are 0.362, 1.775, 0.484 and $1.142 \mathrm{mM} / \mathrm{L}$ against apple juice, compound juice, orange juice and vitamin drink, respectively. It can be seen that the experimental value and actual value of these drinks are similar. It should be noted that all the solutions are filtered with filter papers before the measurements. Otherwise, the juice residues would lower the triboelectric output and influence the sensing process. These results suggest that this self-powered flexible sour sensor can sense AA concentrations and, in the future, it can be acted as gustatory receptors for building electronic tongues.
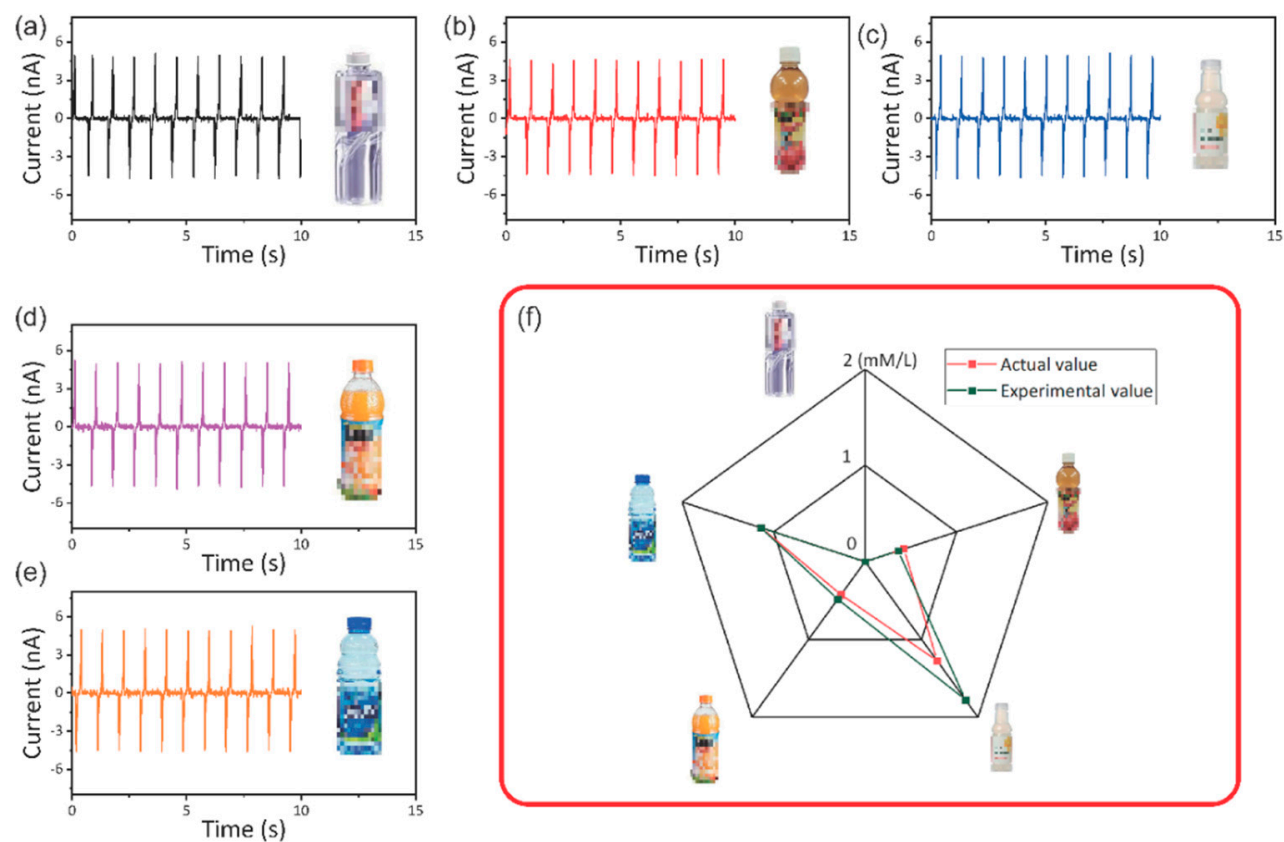

Figure 7. The practical application in detecting ascorbic acid in different drinks. (a-e) The output triboelectric current against mineral water, apple juice, compound juice, orange juice, and vitamin drink, respectively. (f) Corresponding measured response and AA concentration in these drinks. 


\section{Conclusions}

In summary, self-powered flexible sour sensor for detecting ascorbic acid concentration has been fabricated from Ppy/PDMS structure. The material system consists of $\mathrm{Na}_{2} \mathrm{C}_{2} \mathrm{O}_{4}$ Ppy with AAO modification, PDMS and $\mathrm{Cu}$ wire mesh. The sour senor can convert weak energy from body movement into current signal and the biosignal is markedly affected by the concentration of ascorbic acid. Basing on the triboelectrification/enzymatic-reaction coupling effect, the response of the device is up to $34.82 \%$ against $15.625 \mathrm{mM} / \mathrm{L}$ AA solution. Furthermore, the whole process does not involve any extra power source. A practical application has been demonstrated for detecting ascorbic acid concentration of different drinks. This study reports an important advancement in low-cost self-powered nanosystems.

Supplementary Materials: The supplementary materials are available online at https:/ /www.mdpi. com/1424-8220/21/2/373/s1.

Author Contributions: Conceptualization, T.Z.; methodology, T.Z., Q.W. and A.D.; software, Q.W.; validation, T.Z., Q.W. and A.D.; formal analysis, T.Z.; investigation, T.Z.; resources, Q.W. and A.D.; data curation, T.Z.; writing—original draft preparation, T.Z.; writing—review and editing, T.Z.; visualization, T.Z.; supervision, Q.W. and A.D.; project administration, Q.W. and A.D.; funding acquisition, A.D. All authors have read and agreed to the published version of the manuscript.

Funding: This research was funded by the Ministry of Science and Technology of China grant number 2011CB606404.

Acknowledgments: The authors would like to thank Shan Gao, Hui Zeng and Haoxuan He for whose support we are grateful.

Conflicts of Interest: The authors declare no conflict of interest.

\section{References}

1. Augustin, A.; Yi, J.; Clausen, T.; Townsley, W. A Study of LoRa: Long Range \& Low Power Networks for the Internet of Things. Sensors 2016, 16, 1466.

2. Bandodkar, A.; Jeerapan, I.; Wang, J. Wearable Chemical Sensors: Present Challenges and Future Prospects. ACS Sens. 2016, 1, 464-482. [CrossRef]

3. Han, S.; Peng, H.; Sun, Q.; Venkatesh, S.; Chung, K.; Lau, S.; Zhou, Y.; Roy, V. An Overview of the Development of Flexible Sensors. Adv. Mater. 2017, 29, 1700375. [CrossRef] [PubMed]

4. Khan, Y.; Ostfeld, A.; Lochner, C.; Pierre, A.; Arias, A. Monitoring of Vital Signs with Flexible and Wearable Medical Devices. Adv. Mater. 2016, 28, 4373-4395. [CrossRef]

5. Singh, E.; Meyyappan, M.; Nalwa, H. Flexible Graphene-Based Wearable Gas and Chemical Sensors. ACS Appl. Mater. Interfaces 2017, 9, 34544-34586. [CrossRef]

6. Zhu, H.; Wang, X.; Liang, J.; Lv, H.; Tong, H.; Ma, L.; Hu, Y.; Zhu, G.; Zhang, T.; Tie, Z.; et al. Versatile Electronic Skins for Motion Detection of Joints Enabled by Aligned Few-Walled Carbon Nanotubes in Flexible Polymer Composites. Adv. Funct. Mater. 2017, 27, 1606604. [CrossRef]

7. Wang, L.; Jackman, J.; Tan, E.; Park, J.; Potroz, M.; Hwang, E.; Cho, N. High-performance, flexible electronic skin sensor incorporating natural microcapsule actuators. Nano Energy 2017, 36, 38-45. [CrossRef]

8. Lou, Z.; Chen, S.; Wang, L.; Shi, R.; Li, L.; Jiang, K.; Chen, D.; Shen, G. Ultrasensitive and ultraflexible e-skins with dual functionalities for wearable electronics. Nano Energy 2017, 38, 28-35. [CrossRef]

9. Jung, M.; Kim, K.; Kim, B.; Cheong, H.; Shin, K.; Kwon, O.; Park, J.; Jeon, S. Paper-Based Bimodal Sensor for Electronic Skin Applications. ACS Appl. Mater. Interfaces 2017, 9, 26974-26982. [CrossRef]

10. Han, X.; Du, W.; Chen, M.; Wang, X.; Zhang, X.; Li, X.; Li, J.; Peng, Z.; Pan, C.; Wang, Z. Visualization Recording and Storage of Pressure Distribution through a Smart Matrix Based on the Piezotronic Effect. Adv. Mater. 2017, 29, 1701253.

11. Assaf, A.; Cordella, C.; Thouand, G. Raman spectroscopy applied to the horizontal methods ISO 6579:2002 to identify Salmonella sin the food industry. Anal. Bioanal. Chem. 2014, 406, 4899-4910. [CrossRef] [PubMed]

12. Bittel, M.; Cordella, C.; Assaf, A.; Jouanneau, S.; Durand, M.; Thouand, G. Potential of Raman Spectroscopy to Monitor Arsenic Toxicity on Bacteria: Insights toward Multiparametric Bioassays. Environ. Sci. Technol. 2015, 49, 12324-12332. [CrossRef] [PubMed]

13. Assaf, A.; Grange, E.; Cordella, C.; Rutledge, D.; Less, M.; Lahmar, A.; Thouand, G. Evaluation of the impact of buffered peptone water composition on the discrimination between Salmonella enterica and Escherichia coli by Raman spectroscopy. Anal. Bioanal. Chem. 2020, 412, 3595-3604.

14. Murzin, D.; Mapps, D.; Levada, K.; Belaev, V.; Omelyanchik, A.; Panina, L.; Rodionova, V. Ultrasensitive Magnetic Field Sensors for Biomedical Applications. Sensors 2020, 20, 1569. [CrossRef] [PubMed] 
15. Bollella, P.; Sharma, S.; Cass, A.; Antiochia, R. Microneedle-based biosensor for minimally-invasive lactate detection. Biosens. Bioelectron. 2019, 123, 152-159.

16. Kim, J.; Sempionatta, J.; Imani, S.; Hartel, M.; Barfidokht, A.; Tang, G.; Campbell, A.; Mercier, P.; Wang, J. Simultaneous Monitoring of Sweat and Interstitial Fluid Using a Single Wearable Biosensor Platform. Adv. Sci. 2018, 5, 1800880.

17. Yang, Y.; Gao, W. Wearable and flexible electronics for continuous molecular monitoring. Chem. Soc. Rev. 2019, 48, 14651491. [CrossRef]

18. Camillieri, B.; Bueno, M. Artificial finger design for investigating the tactile friction of textile surfaces. Tribol. Int. 2017, 109, 274-284. [CrossRef]

19. Cesini, I.; Ndengue, J.; Chatelet, E.; Faucheu, J.; Massi, F. Correlation between friction-induced vibrations and tactile perception during exploration tasks of isotropic and periodic textures. Adv. Mater. 2018, 120, 330-339.

20. Wang, Z. Zinc oxide nanostructures: Growth, properties and applications. J. Phys. Condens. Matter 2004, 16, R829-R858.

21. Barsan, N.; Weimar, U. Understanding the fundamental principles of metal oxide-based gas sensors; the example of CO sensing with $\mathrm{SnO}_{2}$ sensors in the presence of humidity. J. Phys. Condens. Matter 2003, 15, R813-R839.

22. Pearton, S.; Kang, B.; Kim, S.; Ren, F.; Gila, B.; Abernathy, C.; Lin, J.; Chu, S. GaN-based diodes and transistors for chemical, gas, biological and pressure sensing. J. Phys. Condens. Matter 2004, 16, R961-R994. [CrossRef]

23. Loretta, B.; Oliviero, M.; Vittorio, M.; Emanuel Bojórquez-Quintal and Fabio, Z. Quality by design approach to optimize cladodes soluble fiber processing extraction in Opuntia ficus indica (L.) miller. J. Food Sci. Technol. 2019, 56, 3627-3634. [PubMed]

24. Falk, M.; Psotta, C.; Cirovic, S.; Shleev, S. Non-Invasive Electrochemical Biosensors Operating in Human Physiological Fluids. Sensors 2020, 20, 6352. [CrossRef] [PubMed]

25. Wang, W.; Chen, D.; Liu, J.; Zhu, J.; Zhang, P.; Yang, L.; Chen, H.; Wang, Y. Strain sensor for full-scale motion monitoring based on self-assembled PDMS/MWCNTs layers. J. Phys. D Appl. Phys. 2020, 53, 095405. [CrossRef]

26. Caciotta, M.; Giarnetti, S.; Leccese, F.; Orioni, B.; Oreggia, M.; Pucci, C.; Rametta, S. Flavors mapping by Kohonen network classification of Panel Tests of Extra Virgin Olive Oil. Measurement 2016, 78, 366-372. [CrossRef]

27. Gao, K.; Gao, F.; Du, L.; He, C.; Wan, H.; Wang, P. Integrated olfaction, gustation and toxicity detection by a versatile bioengineered cell-based biomimetic sensor. Bioelectrochemistry 2019, 128, 1-8.

28. Qin, Z.; Zhang, B.; Gao, K.; Zhuang, L.; Hu, N.; Wang, P. A whole animal-based biosensor for fast detection of bitter compounds using extracellular potentials in rat gustatory cortex. Sens. Actuators B Chem. 2017, 239, 746-753.

29. Cole, M.; Covington, J.; Gardner, J. Combined electronic nose and tongue for a flavour sensing system. Sens. Actuators B Chem. 2011, 156, 832-839.

30. Ni, L.; Bronk, P.; Chang, E.; Lowell, A.; Flam, J.; Panzano, V.; Theobald, D.; Griffith, L.; Garrity, A. A gustatory receptor paralogue controls rapid warmth avoidance in Drosophila. Nature 2013, 500, 580-584. [CrossRef]

31. Guerrini, L.; Garcia-Rico, E.; Pazos-Perez, N.; Alvarez-Puebla, R. Smelling, Seeing, Tasting-Old Senses for New Sensing. ACS Nano 2017, 11, 5217-5222. [CrossRef] [PubMed]

32. Alagappan, M.; Immanuel, S.; Sivasubramanian, R.; Kandaswamy, A. Development of cholesterol biosensor using Au nanoparticles decorated f-MWCNT covered with polypyrrole network. Arab. J. Chem. 2020, 13, 2001-2010. [CrossRef]

33. Medina, O.; Shapiro, A.; Shvalb, N. Resistor-Based Shape Sensor for a Spatial Flexible Manifold. IEEE Sens. J. 2017, 17, 4650. [CrossRef]

34. Manalis, S.; Cooper, E.; Indermuhle, P.; Kernen, P.; Wagner, P.; Hafeman, D.; Minne, S.; Quate, C. Microvolume field-effect pH sensor for the scanning probe microscope. Appl. Phys. Lett. 2000, 76, 1072-1074.

35. Xu, G.; Jarjes, Z.; Desprez, V.; Kilmartin, P.; Travas-Sejdic, J. Sensitive, selective, disposable electrochemical dopamine sensor based on PEDOT-modified laser scribed graphene. Biosens. Bioelectron. 2018, 107, 184-191. [CrossRef] [PubMed]

36. Wu, S.; Zeng, Z.; He, Q.; Wang, Z.; Wang, S.J.; Du, Y.; Yin, Z.; Sun, X.; Chen, W.; Zhang, H. Electrochemically Reduced Single-Layer MoS2 Nanosheets: Characterization, Properties, and Sensing Applications. Small 2012, 8, 2264-2270. [CrossRef]

37. Sun, K.; Wei, T.; Ahn, B.; Seo, J.; Dillon, S.; Lewis, J. 3D Printing of Interdigitated Li-Ion Microbattery Architectures. Adv. Mater. 2013, 25, 4539-4543. [CrossRef]

38. Guan, H.; Lv, D.; Zhong, T.; Dai, Y.; Xing, L.; Xue, X.; Zhang, Y.; Zhan, Y. Self-powered, wireless-control, neural-stimulating electronic skin for in vivo characterization of synaptic plasticity. Nano Energy 2020, 67, 104182. [CrossRef]

39. He, H.; Zhao, T.; Guan, H.; Zhong, T.; Zeng, H.; Xing, L.; Zhang, Y.; Xue, X. A water-evaporation-induced self-charging hybrid power unit for application in the Internet of Things. Sci. Bull. 2019, 64, 1409-1417. [CrossRef]

40. Das, P.; Chhetry, A.; Maharjan, P.; Rasel, M.; Park, J. A laser ablated graphene-based flexible self-powered pressure sensor for human gestures and finger pulse monitoring. Nano Res. 2019, 12, 1789-1795.

41. Kang, H.; Zhao, C.; Huang, J.; Ho, D.; Megra, Y.; Suk, J.; Sun, J.; Wang, Z.; Sun, Q.; Cho, J. Fingerprint-Inspired Conducting Hierarchical Wrinkles for Energy-Harvesting E-Skin. Adv. Funct. Mater. 2019, 29, 1903580. [CrossRef]

42. Liu, Y.; Zhong, J.; Li, E.; Yang, H.; Wang, X.; Lai, D.; Chen, H.; Guo, T. Self-powered artificial synapses actuated by triboelectric nanogenerator. Nano Energy 2019, 60, 377-384. [CrossRef]

43. Liu, Z.; Zhao, T.; Guan, H.; Zhong, T.; He, H.; Xing, L.; Xue, X. A self-powered temperature-sensitive electronic-skin based on tribotronic effect of PDMS/PANI nanostructures. J. Mater. Sci. Technol. 2019, 35, 2187-2193.

44. Zhao, T.; Zheng, C.; He, H.; Guan, H.; Zhong, T.; Xing, L.; Xue, X. A self-powered biosensing electronic-skin for real-time sweat Ca2+ detection and wireless data transmission. Smart Mater. Struct. 2019, 28, 085015. 
45. Xue, X.; Qu, Z.; Fu, Y.; Yu, B.; Xing, L.; Zhang, Y. Self-powered electronic-skin for detecting glucose level in body fluid basing on piezo-enzymatic-reaction coupling process. Nano Energy 2016, 26, 148-156. [CrossRef]

46. Zhang, W.; Zhang, L.; Gao, H.; Yang, W.; Wang, S.; Xing, L.; Xue, X. Self-Powered Implantable Skin-Like Glucometer for Real-Time Detection of Blood Glucose Level In Vivo. Nano-Micro Lett. 2018, 10, 32. [CrossRef]

47. He, H.; Zhang, M.; Zhao, T.; Zeng, H.; Xing, L.; Xue, X. A self-powered gas sensor based on PDMS/Ppy triboelectric-gas-sensing arrays for the real-time monitoring of automotive exhaust gas at room temperature. Sci. China Mater. 2019, 62, 1433-1444.

48. Fu, Y.; He, H.; Liu, Y.; Wang, Q.; Xing, L.; Xue, X. Self-powered, stretchable, fiber-based electronic-skin for actively detecting human motion and environmental atmosphere based on a triboelectrification/gas-sensing coupling effect. J. Mater. Chem. C 2017, 5, 1231-1239. [CrossRef]

49. Dai, Y.; Fu, Y.; Zeng, H.; Xing, L.; Zhang, Y.; Zhan, Y.; Xue, X. A Self-Powered Brain-Linked Vision Electronic-Skin Based on Triboelectric-Photodetecing Pixel-Addressable Matrix for Visual-Image Recognition and Behavior Intervention. Adv. Funct. Mater. 2018, 28, 1800275. [CrossRef]

50. Zeng, H.; He, H.; Fu, Y.; Zhao, T.; Han, W.; Xing, L.; Zhang, Y.; Zhan, Y.; Xue, X. A self-powered brain-linked biosensing electronic-skin for actively tasting beverage and its potential application in artificial gustation. Nanoscale 2018, 10, 19987-19994.

51. Liu, Y.; Niu, S.; Wang, Z. Theory of Tribotronics. Adv. Electron. Mater. 2015, 1, 1500124. [CrossRef]

52. Niu, S.; Liu, Y.; Chen, X.; Wang, S.; Zhou, Y.; Lin, L.; Xie, Y.; Wang, Z. Theory of freestanding triboelectric-layer-based nanogenerators. Nano Energy 2015, 12, 760-774. [CrossRef]

53. Niu, S.; Wang, S.; Lin, L.; Liu, Y.; Zhou, Y.; Hu, Y.; Wang, Z. Theoretical study of contact-mode triboelectric nanogenerators as an effective power source. Energy Environ. Sci. 2013, 6, 3576-3593. [CrossRef]

54. Zhao, T.; Fu, Y.; He, H.; Dong, C.; Zhang, L.; Zeng, H.; Xing, L.; Xue, X. Self-powered gustation electronic skin for mimicking taste buds based on piezoelectric-enzymatic reaction coupling process. Nanotechnology 2018, 29, 075501. [CrossRef] 